Available online: http://openjournal.wdh.ac.id/index.php/edudharma

Edu Dharma Journal

ISSN (Print) 2597-890 X ，ISSN (Online) 2686-6366

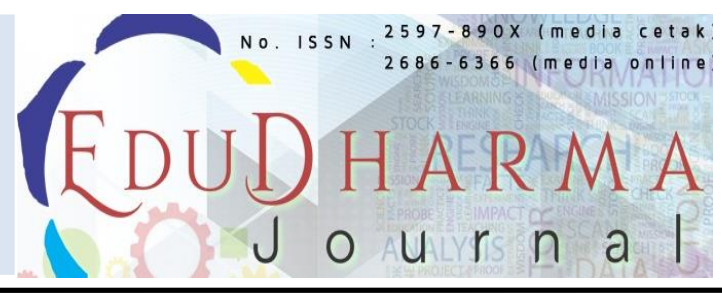

\title{
ANALISIS PENGARUH LATIHAN RENTANG GERAK TERHADAP PENINGKATAN KEKUATAN OTOT DAN AKTIFITAS PERAWATAN DIRI PASIEN STROKE DI RSUD KOTA DEPOK
}

\author{
Liza Puspa Dewi ${ }^{1 *}$, Maria Astrid ${ }^{2}$, Sudibyo Supardi $^{2}$ \\ ${ }^{1}$ STIK Sint Carolus, Mahasiswa Magister Keperawatan, Jakarta 10440, Indonesia \\ ${ }^{2}$ STIK Sint Carolus, Dosen Pengajar, Jakarta 1440 Pos, Indonesia
}

\begin{tabular}{|c|c|}
\hline ARTICLE INFORMATION & $A B S T R A C T$ \\
\hline $\begin{array}{l}\text { *Corresponding Author } \\
\text { Name Liza Puspa Dewi } \\
\text { E-mail: } \\
\text { liza30dewi@gmail.com }\end{array}$ & $\begin{array}{l}\text { Stroke can cause various disorders such as motor deficits in the form of } \\
\text { hemiparesis, hemiplegia, flasidity, and spasticity. This study aims to analyze the } \\
\text { effect of motion range exercise on increasing muscle strength and self-care } \\
\text { activities of stroke patients. This research was conducted from May to July } 2018 \\
\text { in Depok General Hospital with a quasi experiment pre and posttest design on }\end{array}$ \\
\hline $\begin{array}{l}\text { Keywords: } \\
\text { Range motion exercise_1, } \\
\text { Muscle strength_2, } \\
\text { Self-care activities_3 Stroke_4 }\end{array}$ & $\begin{array}{l}\text { divided into two groups, } 88 \text { respondents in the intervention group who were given } \\
\text { treatment according to hospital standards and Motion Range Exercise (MRE) } 4 \\
\text { times a day for } 7 \text { days, then evaluated on the fourth and seventh days and the } \\
\text { control group of } 28 \text { respondents who were given appropriate treatment hospital } \\
\text { standards without additional MRE, then evaluated on the seventh day. Wilcoxon } \\
\text { test showed an increase in muscle strength } 0.74(22.9 \%) \text { and self-care activities } \\
0.53(25.2 \%) \text {, chi square test showed a change in muscle strength } 57.7 \% \text { and } \\
\text { Multivariate Logistic Regression test showed an increase in muscle strength } \\
\text { towards increasing self-care activities } 62.7 \% \text {. The results showed a significant } \\
\text { increase in muscle strength ( } p=0,000) \text { and an increase in self-care activities ( } p \\
=0,000) \text { before and after the intervention. Significantly there was an increase in } \\
\text { muscle strength to increase self-care activity (p }=0.001) \text {. MRE intervention can } \\
\text { increase } 28.9 \text { times muscle strength, thus increasing self-care activities compared } \\
\text { to those not given MRE. It can be concluded that MRE has an effect on increasing } \\
\text { muscle strength and self-care activities. This study recommends the need for } \\
\text { further research and that nurses can apply MRE as nursing interventions to } \\
\text { stroke patients }\end{array}$ \\
\hline $\begin{array}{l}\text { Kata Kunci: } \\
\text { Latihan rentang gerak_1, } \\
\text { Kekuatan otot_2, Aktifitas } \\
\text { perawatan diri_3, } \\
\text { Stroke_4 }\end{array}$ & $\begin{array}{l}\text { A B S T R A K } \\
\text { Stroke dapat menyebabkan berbagai gangguan fungsional seperti defisit motorik } \\
\text { berupa hemiparesis, hemiplegia, flasiditas, dan spastisitas. Penelitian ini bertujuan } \\
\text { menganalisis pengaruh latihan rentang gerak terhadap peningkatan kekuatan otot } \\
\text { dan aktifitas perawatan diri pasien stroke. Penelitian ini dilakukan dari bulan Mei } \\
\text { sampai Juli } 2018 \text { di RSUD Kota Depok dengan quasi experiment pre and posttest } \\
\text { design terhadap } 116 \text { responden yang ditentukan dengan teknik purposive } \\
\text { sampling. Responden dibagi menjadi dua kelompok, yakni } 88 \text { responden } \\
\text { kelompok intervensi yang diberikan perlakuan sesuai standar rumah sakit dan } \\
\text { Latihan Rentang Gerak (LGR) } 4 \text { kali sehari selama } 7 \text { hari, kemudian dievaluasi } \\
\text { pada hari keempat dan hari ketujuh dan kelompok kontrol sebanyak } 28 \text { responden } \\
\text { yang diberikan perlakuan sesuai standar rumah sakit tanpa tambahan LGR, } \\
\text { kemudian dievaluasi pada hari ketujuh. Hasil uji Wilcoxon menunjukkan }\end{array}$ \\
\hline
\end{tabular}




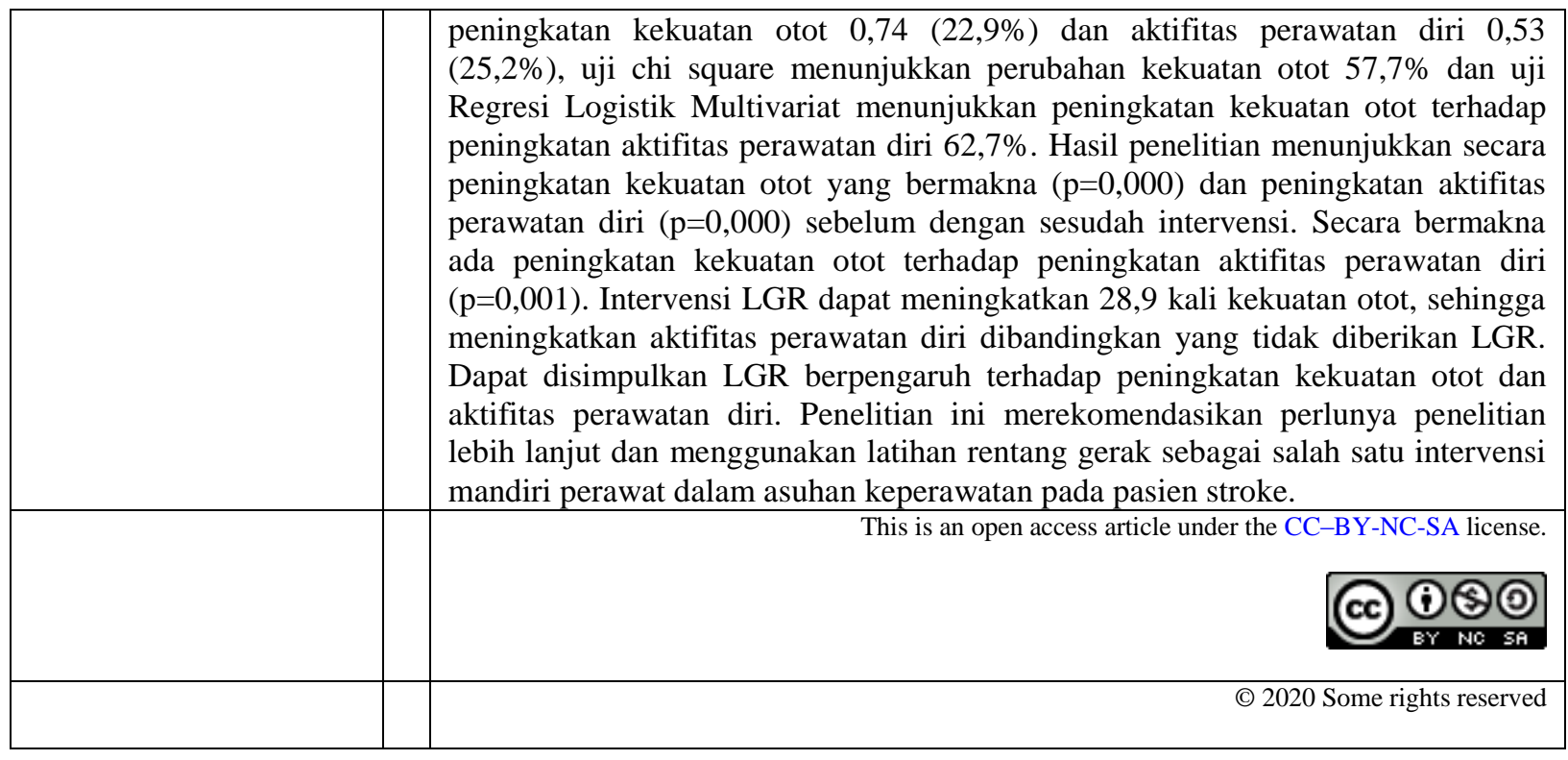




\section{PENDAHULUAN}

Stroke adalah gangguan fungsi saraf lokal dan/atau global pada otak, yang munculnya mendadak, progresif, dan cepat. Merupakan gangguan fungsi syaraf pada otak disebabkan oleh gangguan peredaran darah otak non traumatik (Riskesdas, 2013). Terjadinya stroke bila ada aliran darah yang tidak adekuat ke bagian atau ruang subaraknoid, dan pada stroke iskemik disebabkan karena adanya penyumbatan trombosis atau embolik di dalam pembuluh darah otak (Black dan Hawks, 2014). World Health Organization (WHO) mengungkapkan sebanyak 6 juta orang terkena stroke per tahun dan diperkirakan 8 juta orang meninggal pada tahun 2030 (WHO, 2012). Menurut American Stroke Statistic (2016) di Amerika Serikat, stroke adalah urutan ke-5 penyebab kematian, sekitar 128.978 pasien meninggal per tahun. Setiap 4 menit seseorang meninggal karena stroke, hampir 800.000 (ada 795.000) orang menderita stroke setiap tahun, dan ada 3 4 orang penderita stroke baru dalam setiap 4 detik per orang. Stroke menyebabkan berbagai gangguan fungsional seperti defisit motorik, defisit sensori persepsi, perubahan kognitif dan perilaku, gangguan komunikasi, dan gangguan eliminasi. Tanda dan gejala yang paling khas pada defisit motorik adalah hemiparesis (kelemahan sebagian tubuh kanan atau kiri), hemiplegia (paralisis sebagian tubuh kanan atau kiri), flasiditas (tidak adanya tonus otot/hipotonia), dan spastisitas (peningkatan tonus otot/hipertonia). Selain itu, perubahan fisik lain yang sering dialami penderita stroke adalah kesemutan atau baal pada satu sisi tubuh, mulut menjadi mencong (LeMone, Burke, dan Bauldoff, 2017). Kekuatan otot merupakan kemampuan otot menahan beban eksternal maupun internal. Kekuatan otot berhubungan dengan sistem neuromuskuler, yaitu seberapa besar kemampuan saraf mengaktivasi otot untuk melakukan kontraksi, sehingga semakin banyak otot teraktivasi, maka semakin besar kekuatan yang dihasilkan oleh otot (Brandsma, 2015). Pasien stroke yang mengalami hemiparese dapat mengakibatkan menurunnya aktifitas perawatan diri (disability). Disability pada pasien stroke dapat mengakibatkan ketidakmampuan dan ketergantungan. Maka bila dibiarkan dapat menimbulkan perubahan perilaku, sehingga memperpanjang masa penyembuhan atau pemulihannya, dan dapat mengakibatkan perubahan fisik dan psikis serta komplikasi lainnya. Komplikasi lanjut pada stroke adalah ulkus dekubitus, kontraktur, nyeri bahu (shoulder hand syndrom terjadi pada $27 \%$ ), osteopenia, berbicara pelo atau sulit 
komunikasi atau tidak paham

pembicaraan, kehilangan kemampuan

menelan, gangguan kognitif, dan gangguan psikologis (Black \& Hawks, 2014; Riskesdas, 2013). Menurut State of the Nation Stroke statistics (2016), insiden perubahan fisik pasien stroke meliputi: hemiparese anggota gerak atas $77 \%$, hemiparese anggota gerak bawah $72 \%$, penurunan fungsi visual $60 \%$, gangguan bicara 50\%, penurunan kontrol kandung kemih 50\%, gangguan menelan $45 \%$, aphasia 33\%, depresi 33\%, penurunan kontrol buang air besar (BAB) 33\%, dementia $30 \%$, apatis/kurang perhatian $28 \%$, gangguan emosi dalam 6 bulan 20\%, gangguan emosi setelah 8 bulan $10 \%$. Perubahan fisik yang dialami pasien stroke akan berdampak pada kemampuan pasien dalam melakukan perawatan diri seharihari, seperti makan, berpakaian, kebersihan diri dan lainnya. Ketidakmampuan ini dapat dialami pasien setelah serangan stroke mulai 6 minggu hingga 8 minggu osteoporosis, dan depresi (25-30\%). Keadaan tersebut dapat menyebabkan penurunan kemandirian pasien dalam aktifitas perawatan diri. Defisit motorik mengakibatkan perubahan mobilisasi dan mengganggu fungsi tubuh. Disabilitas akibat stroke menyebabkan perubahan pada status kesehatan fungsional (Lemone, Burke, Bauldoff,
2017). Penanganan pasien stroke untuk mengatasi dan memperbaiki kelemahan atau hemiparese dapat diberikan berupa pengobatan farmakologi dan pengobatan non farmakologi/komplementer (Misbach,J., 2011). Pollock (2014) mengatakan terapi komplementer yang diberikan pada pasien stroke yang mengalami hemiparese dapat berupa intervensi fisik seperti latihan resisten progresif, latihan treadmil, terapi cermin dan latihan rentang gerak. Latihan rentang gerak dapat dilakukan pada pasien yang mengalami hambatan mobilisasi fisik yang bertujuan untuk mempertahankan dan meningkatkan kemampuan fungsional (mempertahankan fungsi dan kesejajaran, mencegah edema ekstremitas, dan mengurangi spastisitas) dan mencegah komplikasi (Lemone, Burke, dan Bauldoff, 2017). Latihan dilakukan untuk meningkatkan atau memperbaiki massa otot dan tonus otot. Pada awalnya dapat meningkatkan kekuatan otot karena menstimulasi motor unit, semakin banyak motor unit yang terlibat, maka akan terjadi peningkatan kekuatan otot, pada pasien hemiparese bila tidak segera ditangani dapat terjadi kecacatan yang permanen (Potter \& Perry, 2009). Serangan stroke berkaitan erat dengan gaya hidup kaum muda yang dapat memicu stroke, seperti makanan siap saji, minuman beralkohol, 
kerja berlebihan, kurang berolahraga dan stress, juga penggunaan obat perangsang, narkoba serta kebiasaan merokok. Pergerakan sendi yang tidak sempurna secara normal dan lengkap dapat meningkatkan serangan stroke. Upaya yang dapat dilakukan dengan menerapkan perilaku sehat segera, antara lain stop merokok, membatasi dan menghindari konsumsi alkohol, tidak mengonsumsi obat-obatan terlarang, olahraga teratur, cukup istirahat, dan mencegah obesitas (kegemukan). Faktor-faktor risiko yang dapat dimodifikasi sebaiknya dikendalikan, seperti melakukan medical check up untuk memonitor kondisi kesehatan. Kebiasaan merokok menyebabkan penumpukan kotoran dibagian dalam pembuluh darah atau aterosklerosis. Serangan stroke sulit diprediksi, dengan mengontrol faktor risiko dapat dikatakan sudah melakukan upaya pencegahan dan sesudah intervensi latihan rentang gerak. Mengetahui perbedaan aktifitas perawatan diri sebelum dan sesudah intervensi latihan rentang gerak. Melakukan analisis pengaruh latihan rentang gerak terhadap peningkatan kekuatan otot dan aktifitas perawatan diri, antara kelompok intervensi dan kelompok kontrol. Berdasarkan kelainan patologis, stroke diklasifikasikan kedalam dua jenis stroke yaitu stroke hemoragik dan stroke non hemoragik. Stroke hemoragik disebabkan pecahnya pembuluh darah di otak yang mengakibatkan perdarahan ke dalam jaringan otak, sedangkan stroke non hemoragik / stroke iskemik disebabkan karena adanya penyumbatan trombosis atau embolik di dalam pembuluh darah otak. Perdarahan yang terjadi di otak dapat mengakibatkan kematian sel otak (Lewis, 2017). Tujuan pada penelitian ini adalah mengetahui pengaruh latihan rentang gerak terhadap peningkatan kekuatan otot dan aktifitas perawatan diri pasien Stroke di RSUD Kota Depok.

\section{METODE PENELITIAN}

Penelitian ini merupakan penelitian kuantitatif menggunakan desain quasi eksperiment, pendekatan consecutive sampling pretest-posttest control group design. Penelitian ini untuk mengetahui pengaruh latihan rentang gerak terhadap peningkatan kekuatan otot dan aktifitas perawatan diri pada pasien Stroke di ruang perawatan di Rumah Sakit Umum Daerah Kota Depok. Subyek dalam penelitian ini berjumlah 116 responden yang terdiri dari 88 responden kelompok intervensi Latihan rentang gerak, 28 responden kelompok kontrol. Pengumpulan data dilakukan pada Bulan Mei - Juli 2018. Latihan rentang gerak dilakukan dan ajarkan di ruang perawatan rawat inap 4 kali sehari selama 
7 hari, tapi bila pasien pulang ke rumah sebelum 7 hari, latihan rentang gerak tetap dilanjutkan di rumah. Selanjutnya hasil pretest dan posttest diolah secara statistik univariat deskriptif, bivariate uji Chi Square dan uji Wilcoxon, dan multivariat
Regresi Logistik Multivariat, untuk mengetahui besarnya pengaruh intervensi latihan rentang gerak terhadap peningkatan kekuatan otot dan aktifitas perawatan diri (Supardi, 2013).

\section{HASIL PENELITIAN DAN PEMBAHASANNYA}

\section{Analisis Univariat, Deskriptif.}

Tabel 1. Distribusi Karakteristik Responden Berdasarkan Usia, Jenis Kelamin, dan Riwayat Stroke Pasien Stroke Di RSUD Kota Depok

\begin{tabular}{|c|c|c|c|c|c|c|}
\hline \multirow{2}{*}{$\begin{array}{c}\text { Karakteristik Pasien } \\
\text { Stroke }\end{array}$} & \multicolumn{2}{|c|}{ Kelompok Intervensi } & \multicolumn{2}{|c|}{ Kelompok Kontrol } & \multicolumn{2}{|c|}{ Total } \\
\hline & Jumlah & $\%$ & Jumlah & $\%$ & Jumlah & $\%$ \\
\hline \multicolumn{7}{|l|}{ Jenis kelamin } \\
\hline Laki-laki & 35 & 39,8 & 16 & 57,1 & 51 & 43,9 \\
\hline Perempuan & 53 & 60,2 & 12 & 42,9 & 65 & 56,1 \\
\hline Total & 88 & 100 & 28 & 100 & 116 & 100 \\
\hline \multicolumn{7}{|l|}{ Usia } \\
\hline$<60$ tahun & 57 & 64,7 & 15 & 53,6 & 72 & 62,1 \\
\hline$\geq 60$ tahun & 31 & 35,3 & 13 & 46,4 & 44 & 37,9 \\
\hline Total & 88 & 100 & 28 & 100 & 116 & 100 \\
\hline \multicolumn{7}{|l|}{ Riwayat stroke } \\
\hline Pertama & 65 & 73,8 & 20 & 71,4 & 85 & 73,3 \\
\hline Berulang $(>1 \mathrm{x})$ & 23 & 26,2 & 8 & 28,6 & 31 & 26,7 \\
\hline Total & 88 & 100 & 28 & 100 & 116 & 100 \\
\hline
\end{tabular}

(Sumber : Data primer, 2018)

Pada tabel 1 Didapatkan data bahwa pasien stroke terbanyak pada perempuan dengan 65 responden $(56,1 \%)$, rentang usia $<60$ tahun terdapat 72 responden $(62,1 \%)$ dan riwayat stroke pada serangan pertama terdapat 85 responden $(73,3 \%)$.

Hasil penelitian ini menunjukkan bahwa jenis kelamin perempuan mempunyai persentase terbesar sebanyak 65 responden $(56,1 \%)$ dibandingkan dengan jenis kelamin laki-laki sebanyak 51 responden (49,9\%). Hal ini disebabkan karena jenis kelamin perempuan memiliki hormon esterogen lebih banyak dari laki-laki. Hormon estrogen berperan dalam perkembangan dan pertumbuhan karakteristik seksual wanita serta proses reproduksi. Hormon estrogen juga berfungsi dalam mengendalikan dan mengatur aktifitas sel-sel ataupun organ. Hormon estrogen diproduksi oleh indung telur selama masa produksi 
atau premenapuse. Hormon berada dalam pembuluh darah dan berdampak pada organ seperti otak, hati, dan sistem motorik (gerak) termasuk otot dan tulang. Jadi hormon esterogen berperan dalam pencegahan stroke (Black, 2014;
Lewis, 2017; LeMone, 2017). Pada penelitian ini responden berjenis kelamin perempuan sebanyak 41 responden yang sudah memasuki masa menoupause dan terdapat 24 responden yang masih dalam masa produktif.

Tabel 2. Distribusi Karakteristik Responden Berdasarkan Karakteristik Klinik pasien Stroke di RSUD Kota Depok

\begin{tabular}{|c|c|c|c|c|c|c|}
\hline \multirow{2}{*}{ Karakteristik Klinik Pasien } & \multicolumn{2}{|c|}{ Intervensi } & \multicolumn{2}{|c|}{ Kontrol } & \multicolumn{2}{|c|}{ Total } \\
\hline & Jumlah & $\%$ & Jumlah & $\%$ & Jumlah & $\%$ \\
\hline \multicolumn{7}{|l|}{ Suhu } \\
\hline$<37,5^{\circ} \mathrm{C}$ & 88 & 100 & 28 & 100 & 116 & 100 \\
\hline$\geq 37,5^{\circ} \mathrm{C}$ & 0 & 0 & 0 & 0 & 0 & 0 \\
\hline \multicolumn{7}{|l|}{ Nadi } \\
\hline$<100 \mathrm{x} /$ menit & 88 & 100 & 28 & 100 & 116 & 100 \\
\hline$\geq 100 \mathrm{x} /$ menit & 0 & 0 & 0 & 0 & 0 & 0 \\
\hline \multicolumn{7}{|l|}{ Tekanan Darah } \\
\hline$<160 / 100 \mathrm{mmHg}$ & 88 & 100 & 28 & 100 & 116 & 100 \\
\hline$\geq 160 / 100 \mathrm{mmHg}$ & 0 & & 0 & 0 & 0 & 0 \\
\hline \multicolumn{7}{|l|}{ Lama rawat } \\
\hline$<7$ hari & 31 & 35,2 & 8 & 28,6 & 39 & 33,6 \\
\hline$\geq 7$ hari & 57 & 64,8 & 20 & 71,4 & 77 & 66,4 \\
\hline Total & 88 & 100 & 28 & 100 & 116 & 100 \\
\hline
\end{tabular}

(Sumber : Data primer, 2018)

Pada tabel 2, Didapatkan data responden menunjukkan persentase terbesar suhu tubuh $<37,5^{\circ} \mathrm{C}(100 \%)$, frekuensi nadi $<$ $100 \mathrm{x} /$ menit $(100 \%)$, tekanan darah < $160 / 100 \mathrm{mmHg}(100 \%)$ dan lama rawat $\geq$ 7 hari $(66,4 \%)$. Distribusi ini tidak dilakukan uji univariat dengan latihan rentang gerak, kekuatan otot, dan aktifitas perawatan diri.

Pada penelitian ini semua temperatur/suhu responden dalam batas normal (antara $\left.36,0^{\circ} \mathrm{C}-37,5^{\circ} \mathrm{C}\right)$, frekuensi nadi antara 60 - $100 \mathrm{x} /$ menit, dan tekanan darah tidak terdapat yang lebih dari 160/100 $\mathrm{mmHg}$, hal ini dikarenakan pasien stroke yang mengalami komplikasi hipertensi sudah mendapatkan terapi pengobatan yaitu dengan pemberian obat antihipertensi seperti Amlodipin, Catopril atau Nifedipine.

Lama rawat pasien stroke banyak yang dirawat $\geq 7$ hari dibandingkan yang dirawat $<7$ hari, baik kelompok intervensi maupun kelompok kontrol, standar rawat di RSUD Kota Depok antara 7 sampai 14 hari (tergantung dari kondisi pasien). Pemulangan pasien harus sesuai evaluasi pemulihan dan 
kesembuhan pasien stroke oleh dokter penanggung jawab pasien (DPJP).

Tabel 3. Distribusi Responden Berdasarkan Kekuatan Otot Sebelum dan Sesudah Intervensi Latihan Rentang Gerak Pasien Stroke Di RSUD Kota Depok

\begin{tabular}{|c|c|c|c|c|c|c|c|c|}
\hline \multirow{3}{*}{ Kekuatan Otot } & \multicolumn{4}{|c|}{ Intervensi } & \multicolumn{4}{|c|}{ Kontrol } \\
\hline & \multicolumn{2}{|c|}{ Sebelum } & \multicolumn{2}{|c|}{ Sesudah } & \multicolumn{2}{|c|}{ Sebelum } & \multicolumn{2}{|c|}{ Sesudah } \\
\hline & $\mathrm{n}$ & $\%$ & $\mathrm{n}$ & $\%$ & $\mathrm{n}$ & $\%$ & $\mathrm{n}$ & $\%$ \\
\hline 1 & 0 & 0,0 & 0 & 0,0 & 0 & 0,0 & 0 & 0,0 \\
\hline 2 & 20 & 22,7 & 0 & 0,0 & 8 & 28,6 & 7 & 25,0 \\
\hline 3 & 28 & 31,8 & 23 & 26,1 & 12 & 42,8 & 13 & 46,4 \\
\hline 4 & 40 & 45,5 & 45 & 51,1 & 8 & 28,6 & 7 & 25,0 \\
\hline 5 & 0 & 0,0 & 20 & 22,7 & 0 & 0,0 & 1 & 3,6 \\
\hline Total & 88 & 100 & 88 & 100 & 28 & 100 & 28 & 100 \\
\hline
\end{tabular}

(Sumber : Data primer, 2018)

Berdasarkan tabel 3, diperoleh data gambaran kekutatan otot hasil ukur MMST sebelum dilakukan intervensi memiliki persentase terbesar pada kelompok intervensi dengan nilai 4 sebanyak $40(45,5 \%)$ responden dan pada kelompok kontrol dengan nilai 3 sebanyak $12(42,8 \%)$ responden. Sedangkan setelah intervensi pada nilai 4 sebanyak $45 \quad(51,1 \%)$ responden dan pada kelompok kontrol nilai 3 sebanyak $13 \quad(46,4 \quad \%)$ responden.

Tabel 4. Distribusi Responden Berdasarkan Aktifitas Perawatan Diri Sebelum dan Sesudah diberikan Latihan Rentang Gerak Pasien Stroke Di RSUD Kota Depok

\begin{tabular}{|c|c|c|c|c|c|c|c|c|}
\hline \multirow{3}{*}{ Aktifitas Perawatan Diri } & \multicolumn{4}{|c|}{ Intervensi } & \multicolumn{4}{|c|}{ Kontrol } \\
\hline & \multicolumn{2}{|c|}{ Sebelum } & \multicolumn{2}{|c|}{ Sesudah } & \multicolumn{2}{|c|}{ Sebelum } & \multicolumn{2}{|c|}{ Sesudah } \\
\hline & $\mathrm{n}$ & $\%$ & $\mathrm{n}$ & $\%$ & $\mathrm{n}$ & $\%$ & $\mathrm{n}$ & $\%$ \\
\hline \multicolumn{9}{|l|}{ Barthel Index } \\
\hline $1($ Skor $0-20)$ & 10 & 11,4 & 2 & 2,3 & 0 & 0 & 0 & 0,0 \\
\hline $2($ Skor $21-60)$ & 59 & 67,0 & 35 & 39,8 & 20 & 71,4 & 19 & 67,9 \\
\hline $3($ Skor $61-90)$ & 19 & 21,6 & 45 & 51,1 & 7 & 25,0 & 8 & 28,6 \\
\hline 4 (Skor $91-99)$ & 0 & 0 & 6 & 6,8 & 1 & 3,6 & 1 & 3,6 \\
\hline Total & 88 & 100 & 88 & 100 & 28 & 100 & 28 & 100 \\
\hline
\end{tabular}

Kekuatan otot merupakan kemampuan otot dalam menahan beban eksternal maupun internal. Kekuatan otot berhubungan dengan system neuromuskuler, yaitu seberapa besar kemampuan saraf mengaktifasi otot untuk melakukan kontraksi, sehingga semakin banyak otot teraktivasi, maka semakin besar kekuatan yang dihasilkan oleh otot (Brandsma, 2015). Kontraksi otot terjadi ketika stimulus memicu serat otot pada individu (Black, 2014). 
(Sumber : Data primer, 2018)

Berdasarkan tabel 4, didapatkan data aktifitas perawatan diri dengan menggunakan skala ukur Barthel Index didapatkan hasil sebelum pelaksanaan intervensi pada kelompok interevensi mempunyai nilai 2 sebanyak $59(67 \%)$ responden dan setelah intervensi nilainya menjadi 3 sebanyak $45 \quad(51,1 \%)$ responden, sedangkan pada kelompok kontrol padapenilaian pertama memiliki nilai 2 sebanyak $20(71,4 \%)$ responden dan pada penilaian akhir memiliki nilai 2 sebanyak $19(67,9 \%)$ responden.

Konsep kemampuan fungsional telah menjadi bagian dari proses keperawatan rehabilitasi, karena sudah menjadi perencanaan, implementasi dan evaluasi. Tujuan dilakukan pengkajian status kemampuan fungsional adalah untuk menentukan status fungsional fisik, kebutuhan intervensi dan pelayanan, serta memonitor perkembangan kemampuannya. Pengkajian yang dilakukan untuk dapat mendeskripsikan kemampuan dan keterbatasan pasien untuk melakukan berbagai ketrampilan individual yang termasuk diantaranya dalam melakukan Actifity daily living $(A D L)$, vokasional, aktifitas kesenangan, interaksi sosial, dan perilaku lainnya.

\section{Uji Beda Berpasangan Uji Wilcoxon dan Non Parametrik Dengan Chi-Square.}

Tabel 5. Analisis Perbedaan Rata-Rata Kekuatan Otot Sebelum dan Sesudah Intervensi Antara Kelompok Intervensi dan Kelompok Kontrol Pasien Stroke di RSUD Kota Depok, 2018

\begin{tabular}{lccccc}
\hline \multirow{2}{*}{ Kekuatan Otot } & \multicolumn{2}{c}{ Rata-Rata } & \multicolumn{2}{c}{ Peningkatan } & \multirow{2}{*}{$\mathrm{p}$} \\
\cline { 2 - 5 } & Sebelum & Sesudah & Nilai & $\%$ & 0,000 \\
Intervensi & 3,23 & 3,97 & 0,74 & 22,9 & 0,157 \\
Kontrol & 3,00 & 3,07 & 0,07 & 2,3 & \multirow{2}{*}{0} \\
\hline
\end{tabular}

(Sumber : Data primer, 2018)

Berdasarkan tabel 5, didapatkan hasil rata-rata kekuatan otot sebelum latihan rentang gerak pada kelompok intervensi 3,23 dan pada kelompok kontrol adalah 3,00. Sedangkan hasil rata-rata kekuatan otot sesudah intervensi pada kelompok intervensi menjadi 3,97 dan kelompok kontrol menjadi 3,07. Berdasarkan hasil tersebut dapat disimpulkan bahwa terjadi peningkatan nilai kekuatan otot pada kelompok intervensi sebesar 0,74 $(22,9 \%)$ dan pada kelompok kontrol sebesar $0,07(2,3 \%)$.

Secara statistik menunjukkan ada perbedaan yang signifikan terhadap kekuatan otot sebelum dengan sesudah intervensi latihan rentang gerak pada 
kelompok intervensi dengan $\mathrm{p}=0,00$ $(\mathrm{p}<0,05)$ dan tidak terdapat adanya perbedaan yang signifikan pada kelompok kontrol dengan $\mathrm{p}=0,157$ ( $>>0,05)$, sehingga disimpulkan bahwa latihan rentang gerak berpengaruh terhadap peningkatan kekuatan otot pasien stroke. Hasil penelitian ini sesuai dengan penelitian yang dilakukan oleh Cahyati (2013) yang menunjukkan bahwa kekuatan otot dapat meningkat pada kedua kelompok intervensi latihan rentang gerak dan terdapat perbedaan yang signifikan diantara kedua kelompok intervensi dan kelompok kontrol.

Tabel 6, Analisis Perbedaan Rata-Rata Latihan Rentang Gerak Terhadap Aktifitas Perawatan Diri Sebelum dan Sesudah Intervensi Antara Kelompok Intervensi dan Kelompok Kontrol Pasien Stroke di RSUD Kota Depok

\begin{tabular}{lccccc}
\hline \multirow{2}{*}{ Aktifitas Perawatan Diri } & \multicolumn{2}{c}{ Rata-Rata } & \multicolumn{2}{c}{ Peningkatan } & \multirow{2}{*}{$\mathrm{p}$} \\
\cline { 2 - 5 } Intervensi & Sebelum & Sesudah & Nilai & $\%$ & \\
\hline Kontrol & 2,10 & 2,63 & 0,53 & 25,2 & 0,000 \\
\hline Sumber: Data primer, 2018) & 2,32 & 2,36 & 0,04 & 1,7 & 0,317 \\
\hline
\end{tabular}

(Sumber : Data primer, 2018)

Berdasarkan tabel 6, didapatkan data adanya peningkatan nilai rata-rata aktifitas perawatan diri pada kelompok intervensi sebelum intervensi 2,10 dan setelah intervensi menjadi 2,63, sehingga terdapat peningkatan nilai rata-rata sebesar $0,53 \quad(25,2 \%)$, sedangkan pada kelompok kontrol pada penilaiana awal mendapatkan nilai ratarata 2,32 dan setelah pada penilaian akhir mendapatkan nilai rata-rata 2,36, sehingga didapatkan adanya peningkatan nilai rata-rata sebesar 0,04 $(1,7 \%)$. dengan $\mathrm{p}=0,317(>0,05)$ berarti tidak signifikan ada peningkatan pada kelompok kontrol. Hasil uji statistik menunjukkan nilai $\mathrm{p}=0,000$ $(\mathrm{p}<0,005)$, berarti ada perbedaan yang sangat signifikan aktifitas perawatan diri sebelum dan sesudah intervensi pada kelompok intervensi

Secara statistik menunjukkan ada perbedaan yang signifikan terhadap aktifitas perawatan diri sebelum dengan sesudah intervensi latihan rentang gerak pada kelompok intervensi dengan $\mathrm{p}=$ $0,000(\mathrm{p}<0,05)$ dan tidak terdapat adanya perbedaan yang signifikan pada kelompok kontrol dengan $\mathrm{p}=0,327$ ( $\mathrm{p}$ $>0,05)$, sehingga disimpulkan bahwa latihan rentang gerak berpengaruh terhadap peningkatan aktifitas perawatan diri pasien stroke. 


\section{Uji Regresi Linear Logistik.}

Tabel 7. Pengaruh Latihan Rentang Gerak, Usia, Jenis Kelamin, Riwayat Stroke Secara Simultan Terhadap Peningkatan Kekuatan Otot Pasien Stroke di RSUD Kota Depok

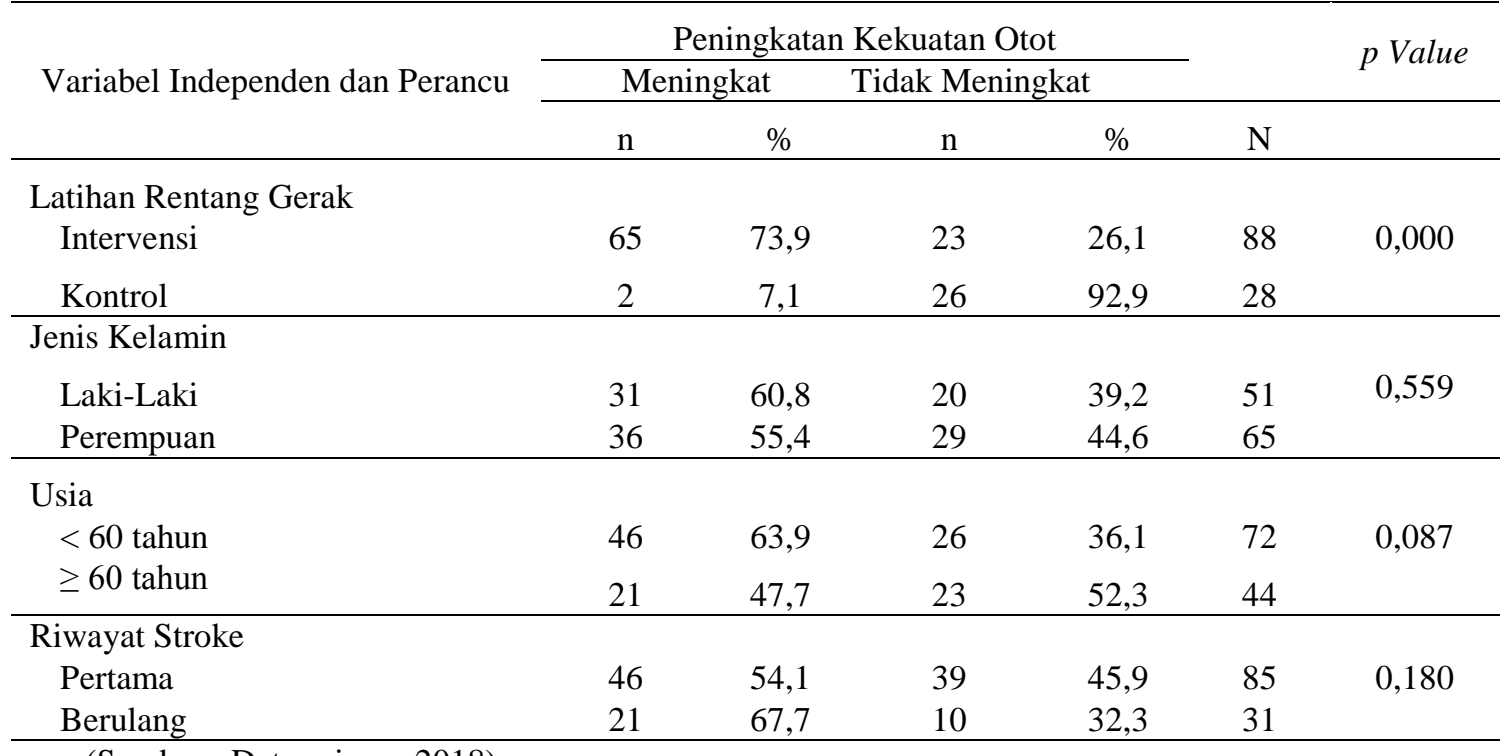

(Sumber : Data primer, 2018)

Berdasarkan tabel 7, didapatkan data bahwa latihan rentang gerak dapat meningkatkan kekuatan otot pada 65 $(73,9 \%)$ responden pada kelompok intervensi dengan $\mathrm{p}=0,000(\mathrm{p}<0,05)$, yang berarti latihan rentang gerak secara signifikan dapat meningkatan kekuatan otot; jenis kelamin pada perempuan sebanyak $36(55,4 \%)$ responden dan lakilaki sebanyak $31 \quad(60,8 \%)$ responden dengan $p=0,559(p>0,05)$, yang berarti jenis kelamin tidak signifikan mempengaruhi peningkatan kekuatan otot; usia responden yang $<60$ tahun sebanyak $46(63,9 \%)$ responden dengan $p$ $=0,087(\mathrm{p}>0,05)$, yang berarti usia tidak signifikan mempengaruhi peningkatan kekuatan otot; riwayat stroke responden penelitian ini majoritas terjadi pada serangan pertama sebanyak $46(54,1 \%)$ responden dan pada serangan stroke ke-2 ada $21(67,7 \%)$ responden dengan $\mathrm{p}=0,189(\mathrm{p}>0,05)$, yang berarti riwayat stroke tidak signifikan mempengaruhi peningkatan kekuatan otot. Berdasarkan data dapat disimpulkan bahwa latihan rentang gerak baik dilakukan pada pasien stroke, tapi tidak dipengaruhi oleh usia, jenis kelamin, dan riwayat stroke.

Pada penelitian ini angka kejadian stroke pada wanita lebih banyak daripada lakilaki. Dari wawancara dengan seluruh pasien stroke wanita mengatakan, hal ini dipengaruhi kebiasaan konsumsi makanan lebih menyukai gorenggorengan dan sayur berkuah santan. 
Tabel 8. Pengaruh Latihan Rentang Gerak, Usia, Jenis Kelamin, Riwayat Stroke Secara Simultan Terhadap Peningkatan Kekuatan Otot Pasien Stroke di RSUD Kota Depok

\begin{tabular}{|c|c|c|c|c|c|c|}
\hline & & & & & 95\% C.I.for & $\mathrm{KP}(\mathrm{B})$ \\
\hline & & B & Sig. & $\operatorname{Exp}(B)$ & Lower & Upper \\
\hline Step $1^{\mathrm{a}}$ & LRG & 3,515 & 0,001 & 33,617 & 4,248 & 266,008 \\
\hline & JK & $-0,549$ & 0,230 & 0,577 & 0,235 & 1,417 \\
\hline & LR & 0,103 & 0,824 & 1,108 & 0,448 & 2,742 \\
\hline & Usia & $-0,550$ & 0,253 & 0,577 & 0,225 & 1,481 \\
\hline & $\mathrm{RS}$ & $-0,423$ & 0,417 & 0,655 & 0,236 & 1,819 \\
\hline Step $2^{\mathrm{a}}$ & LRG & 3,522 & 0,001 & 33,837 & 4.271 & 268,074 \\
\hline & JK & $-0,570$ & 0,203 & 0,565 & 0,235 & 1,361 \\
\hline & Usia & $-0,531$ & 0,262 & 0,588 & 0,232 & 1,487 \\
\hline & $\mathrm{RS}$ & $-0,424$ & 0,416 & 0,655 & 0,236 & 1,818 \\
\hline Step $3^{\mathrm{a}}$ & LRG & 3,497 & 0,001 & 33,030 & 4,185 & 260,685 \\
\hline & $\mathrm{JK}$ & $-0,515$ & 0,242 & 0,598 & 0,252 & 1,417 \\
\hline & Usia & $-0,655$ & 0,145 & 0,520 & 0,216 & 1,252 \\
\hline Step $4^{\mathrm{a}}$ & LRG & 3,364 & 0,001 & 28,911 & 3,742 & 223,357 \\
\hline & Usia & $-0,706$ & 0,112 & 0,493 & 0,207 & 1,179 \\
\hline Step $5^{a}$ & LRG & 3,387 & 0,001 & 29,571 & 3,848 & 227,261 \\
\hline
\end{tabular}

(Sumber : Data primer, 2018)

Berdasarkan tabel 8, didapatkan data pada Step $4^{\mathrm{a}}$ dengan kesimpulan bahwa latihan rentang gerak bermakna terhadap kekuatan otot, hasil yang didapat latihan rentang gerak meningkatkan kekuatan otot meningkat 28,9 kali dibandingkan yang tidak diberikan latihan rentang gerak.

Penelitian yang dilakuan Andarwati, N.A. (2013), menunjukkan adanya perbedaan nilai kekuatan otot sebelum dan setelah dilakukan latihan Latihan rentang gerak selama 7 hari dengan frekuensi latihan 1 kali sehari. Dibandingkan Latihan rentang gerak yang dilakukan 4 kali setiap hari selama 7 hari dapat meningkatkan kontraksi otot, sehingga kontraksi otot yang diakibatkan oleh kontraksi masing-masing komponen sarkomer. Kontraksi sarkomer disebabkan oleh interaksi antara miosin dakam filamen tebal dan aktin dalam filamen tipis, yang saling melekat dengan adanya peningkatan lokal kadar ion kalsium. Filamen tebal dan tipis saling meluncur satu sama lain. Ketika kadar kalsium dalam sarkomer menurun, filamen miosin dan aktin berhenti berinteraksi dan sarkomer kembali ke panjang istirahat awalnya (relaksasi). Aktin dan miosin tidak dapat berinteraksi bila tak ada kalsium. Serabut otot akan berkontraksi sebagai respon terhadap rangsangan listrik, bila terangsang maka sel otot akan membangkitkan 
suatu potensial aksi serupa dengan yang terlihat pada sel saraf. Potensial aksi ini akan menjalar sepanjang membran sel dan mengakibatkan pelepasan ion kalsium ke dalam sel

Tabel 9. Pengaruh Antara Peningkatan Kekuatan Otot Terhadap Peningkatan Aktifitas Perawatan Diri Pasien Stroke di RSUD Kota Depok, 2018

\begin{tabular}{|c|c|c|c|c|c|c|c|}
\hline \multirow{4}{*}{$\begin{array}{c}\text { Peningkatan Kekuatan } \\
\text { Otot }\end{array}$} & \multicolumn{4}{|c|}{ Peningkatan Aktifitas } & \multirow{3}{*}{\multicolumn{2}{|c|}{ Total }} & \multirow{4}{*}{$\begin{array}{c}p \\
\text { Value }\end{array}$} \\
\hline & & & $\tan \mathrm{Di}$ & & & & \\
\hline & \multicolumn{2}{|c|}{ Meningkat } & \multicolumn{2}{|c|}{ Tidak Meningkat } & & & \\
\hline & $\mathrm{n}$ & $\%$ & $\mathrm{n}$ & $\%$ & $\mathrm{n}$ & $\%$ & \\
\hline Meningkat & 37 & 62,7 & 10 & 17,5 & 47 & 40,51 & 0,001 \\
\hline Tidak Meningkat & 22 & 37,3 & 47 & 82,5 & 69 & 59,48 & \\
\hline Total & 59 & 100 & 57 & 100 & 116 & 100 & \\
\hline
\end{tabular}

(Sumber : Data primer, 2018)
Berdasarkan tabel 9, didapatkan data adanya peningkatan aktifitas perawatan diri sebanyak 59 (51\%) responden, dan yang tidak meningkatkan aktifitas perawatan diri sebanyak 57 (49\%) responden, kesimpulan bahwa kekuatan otot yang meningkat memberikan peningkatan aktifitas perawatan diri dengan $\mathrm{p}=0,001(\mathrm{p}<0,005)$.

Penelitian ini menunjukkan bahwa program rehabilitasi efektif dalam meningkatkan status fungsional pasien dan mengurangi ketergantungan pasien stroke. Program rehabilitasi dapat mempengaruhi perkembangan keperawatan yang holistik dan individual penting di semua tatanan dan fokus pada mempromosikan pencapaian potensi dan kemampuan aktifitas pengaruh yang signifikan terhadap penyembuhan saraf. Asuhan otot yang sebelumnya tersimpan dalam organel khusus yang dinamakan retikulum sarkoplasmikum (Smeltzer \& Bare, 2013). perawatan diri yang maksimal (Lemone, 2017).

\section{KESIMPULAN}

Deskripsi pasien stroke terbanyak adalah perempuan $56,1 \%$, rentang usia $<60$ tahun $62,1 \%$ dan riwayat stroke sebagai serangan pertama $73,3 \%$. Distribusi pasien stroke persentase terbesar suhu tubuh $<100 \mathrm{x} /$ menit $(100$ $\%$ ), tekanan darah $<160 / 100 \mathrm{mmHg}$ $(100 \%)$ dan lama rawat $\geq 7$ hari $(66,4 \%)$. Rerata nilai kekuatan otot dengan skala ukur MMST pasien stroke kelompok intervensi sebelum latihan rentang gerak pada skor $4(45,5 \%)$, sedangkan kelompok kontrol sebelum latihan rentang gerak pada skor 3 $(42,8 \%)$. Rerata nilai kekuatan otot dengan skala ukur Barthel Index pasien stroke kelompok intervensi sebelum 
latihan rentang gerak dengan skor 2 (67\%) dan kelompok kontrol sebelum latihan rentang gerak pada skor 2 (71,4\%). Latihan rentang gerak meningkatkan kekuatan otot pasien stroke kelompok intervensi sebesar $22,9 \%$ dengan $\mathrm{p}$ value 0,000 yang artinya latihan rentang gerak bermakna secara signifikan terhadap peningkatan kekuatan otot pasien stroke pada kelompok intervensi dan kelompok kontrol sebesar 2,3\% dengan $\mathrm{p}$ value 0,157 yang berarti latihan rentang gerak tidak bermakna terhadap peningkatan kekuatan otot kelompok intervensi. Latihan rentang gerak meningkatkan aktifitas perawatan diri pasien stroke pada kelompok intervensi sebesar $25,2 \%$ dengan $\mathrm{p}$ value 0,000 yang berarti latihan rentang gerak bermakna terhadap peningkatan aktifitas perawatan diri kelompok intervensi dan kelompok kontrol sebesar 1,7\% dengan $\mathrm{p}$ value 0,317 yang berarti latihan

\section{DAFTAR PUSTAKA}

American Heart Association (AHA). (2015). Heart Disease and Stroke Statistic. http://www..stroke.org. Diakses pada tanggal 12 Agustus 2017.

Black, M.J \& Hawks, H.J. (2014). Keperawatan Medikal Bedah: manajemen Klinis untuk Hasil rentang gerak tidak bermakna terhadap peningkatan aktifitas perawatan diri kelompok kontrol. Latihan rentang gerak dengan $\mathrm{p}$ value $0,000(<0,05)$ signifikan peningkatan kekuatan otot, jenis kelamin dengan $\mathrm{p}$ value 0,559 (> $0,05)$ tidak signifikan, usia dengan $\mathrm{p}$ value 0,087 (>0,05) tidak signifikan, riwayat stroke dengan $\mathrm{p}$ value 0,189 (> 0,05) tidak signifikan. Maka dapat disimpulkan bahwa latihan rentang gerak baik dilakukan pada pasien stroke, tapi tidak dipengaruhi oleh usia, jenis kelamin, dan riwayat stroke. 1. Latihan rentang gerak mempunyai kemungkinan meningkatkan kekuatan otot pasien stroke 28,9 kali dibandingkan yang tidak diberikan latihan rentang gerak. 2. Peningkatan kekuatan otot berpengaruh secara secara bermakna terhadap peningkatan aktifitas perawatan diri pasien stroke $\mathrm{p}$ value 0,001 .

yang Diharapkan. (Edisi 8). Singapore: Elsevier Pte Ltd.

Brandsma, W., \& Schreuders, T.A.R. (2015). Clinical Assessement Recomendation Manual Strength Testing of the Muscles of the Hand and Wrist, 1-16.

Cahyati, Y. (2011). Perbandingan Latihan ROM Unilateral dan Latihan ROM Bilateral terhadap Kekuatan Otot Pasien Hemiparese Akibat Stroke 
Iskemik di RSUD Kota

Tasikmalaya dan RSUD Kabupaten

Ciamis. Tesis Publikasi. Diakses

21 Januari 2018.

LeMone, P., Burke, K.M., Bauldoff, G. (2017). Buku Ajar Keperawatan Medikal Bedah. Gangguan Muskuloskeletal. Jakarta: Penerbit Buku Kedokteran EGC.

Lewis, S.L., et.all. (2017). Medical Surgical Nursing. Assessment and Management of Clinical Problems. 10th Edition. Elsevier Mosby: St.Louis, Missouri.

Misbach, J., et.al. (2011). Guideline Stroke Tahun 2011. ISBN 978-979244277. Jakarta: Perhimpunan Dokter Spesialis Saraf Indonesia (PERDOSSI).

Potter, P.A., Perry, A.G., Stokert, P., \& Hall, A. (2017). Fundamental of Nursing (9th ed.). St.Louis, Missouri: Elsevier.

Poolock, A., Se, F., Mc, B., Langhorne, P., Ge, M., Mehrholz, J., \& F, V.W. (2014). Interventions for improving upper limb function after stroke (Review), (11).

Rikesdas (2013). Badan Penelitian dan Pengembangan Kesehatan Kementrian Kesehatan RI Tahun 2013. Diakses pada tanggal 17 Januari 2018.

Supardi, S., dan Rustika (2013). Metodologi Riset Keperawatan. Jakarta : Penerbit Trans Info Media.
Stroke Association. (2016). State Of The Nation Stroke Statistics January 2017. Together We Can Conquer Stroke. https://www.stroke.org.uk. Di akses pada tanggal 5 Februari 2018. The 